\title{
Ficção científica, a estética cyberpunk e o eterno Blade Runner
}

\author{
Por Carlos H. Carvalho
}

Para muitos, Blade Runner de 1982 é um filme único. A narrativa assombrosa, cercada de charmes senis de uma Hollywood capitalista e um novo diretor inauguram no mundo mais um tombamento cult, nas páginas de discussões da atualidade e entre os fóruns de cinema modernos, Blade Runner é uma pérola resguardada com todas as forças, sua extrema melancolia e o pesar filosófico dão um certo charme na obra, que é uma entre as várias obras de ficção científica que carregam discussões filosóficas nas suas histórias. Um gênero transcendente, penso assim, a ficção científica desde seu início inaugura uma nova maneira artística de se discutir, de mentir - como a autora Ursula K. LeGuin trata o sci fi , e discorrer sobre algo, é justamente com clássicos absolutos da literatura que podemos identificar um traço grandiosamente fantasioso e carregado de pensar filosófico, Frankenstein de Mary Shelley (1818) é um pilar do gênero, e ao mesmo tempo um dos romances mais conhecidos da história da literatura no geral, tal movimento artístico tem esta capacidade: transitar entre um conhecimento e uma literatura popular e um espaço mais reservado também, de supostamente poucos. Ainda discorrendo sobre, a ficção científica e a filosofia nutrem um objeto em comum, o experimentar. Do alemão gendankenexperiment, a experiência de pensamento na filosofia é um alicerce fundamental, desde sua antiguidade com Aristóteles e Platão, e que ecoa na ficção de modo geral, mais precisamente na ficção científica: experimentar pensares e diferentes maneiras que podem ser lidas como "extrapoladas" é um ponto fundamental no gênero, aspecto o qual sua lady sempre gostou de tratar, Ursula K. LeGuin, no prefácio de sua magnum opus A Mão Esquerda da Escuridão (1969), ressoa:

Toda ficção é metáfora. Ficção científica é metáfora. O que a separa das formas mais antigas da ficção parece ser o uso de novas metáforas, tiradas de alguns grandes dominantes de nossa vida contemporânea - ciência, todas as ciências, entre ela a tecnologia e as perspectivas relativista e histórica. A viagem espacial é uma 
dessas metáforas; assim como a sociedade alternativa, a biologia alternativa; o futuro também. O futuro, em ficção, é uma metáfora. (LEGUIN, Ursula K. Aleph, 2014, pág. 11)

Com uma capacidade exemplar, o gênero também carrega uma característica similar aos outrem: a de se adaptar com o tempo, mas é única por sua inventividade de não prever, mas utilizar as inovações e mudanças em suas metáforas e experiências. A ficção científica pulp, por volta da década de 1930 e 1940 discutia sobre temas mais próximos daquela realidade: as pesquisas sobre o universo, a visão sobre o mundo lá fora, a possível vida alienígena... Tema que foi moldado com o decorrer do tempo, e na década de 1960, por exemplo, surge 2001: Uma Odisséia no Espaço, de um impacto não só literário no gênero, mas também cinematográfico, o chamado "primeiro filme sério de ficção científica" que até o momento carregava um status de filmes B, onde o mais científico era um alienígena assediando garotas num celeiro de fazenda. 2001 nasce em um período científicotecnológico muito próximo de sua narrativa: o de expansão espacial, descobrimento da Lua, das estações, do universo ao redor, e por fim da odisseia que como o homem antigo vivia com o mar, o homem moderno vivia com o espaço, aos Homeros astronautas do século XX. Nos anos seguintes, temas mais sedutores surgem conforme a tecnologia avança, na década de 1980, histórias distópicas, corrupção do homem, destruição ambiental e os robôs encarnados são discussões presentes, e com o avanço a partir das narrativas dos anos 1990 e 2000, surge, por exemplo, no gênero as discussões de biotecnologia, bioética e o avanço da modificação do homem sobre a própria natureza biológica humana, clonagem, e afins, por fim, na nossa era atual, a discussão tecnológica é encarnada nas mídias sociais, nos avanços da tecnologia no nosso cotidiano, do suprir humano e o avanço materialtecnológica, um eco dessa nossa contemporaneidade é o fenômeno Black Mirror, série antológica que trata justamente desta temática.

Além da experiência de pensamento e da característica de adaptação com o tempo, a ficção científica ostenta uma leitura minha fundamental para pensarmos nossa realidade, a de grito de voz de minorias sociais. Originada por uma mulher e muita das vezes vista como um gênero somente de homens brancos, cis e héteros, a ficção científica detém subgêneros e tópicos de discussão cruciais para os debates de gênero, raça, sexualidade e afins. Um dos exemplos citados acima, Ursula K. LeGuin é precursora no sentido, de introduzir discussões sobre política, gênero, sociedade e sexualidade em suas várias obras que 
transitam entre o tradicional sci fi e a fantasia, justamente por Ursula e muitos outros captarem o sentido antropológico, cultural e social da nossa sociedade e implementar em histórias do tipo, podemos ver uma relação estridente entre a ficção científica, um suposto gênero menor, às discussões sociais, nas histórias mirabolantes, tratamos de diferenças, de desigualdades: seres alienígenas, vampiros, robôs e inteligências artificiais, são nessas discussões de diversidades que devemos pensar nossas diversidades humanas, discussões de gênero, de sexualidade e de raça são temas permeadores na literatura e no cinema de sci fi. Outro grande exemplo é Octavia Butler, autora negra de ficção científica, que encontra nas páginas mirabolantes e experiências de pensar uma maneira de representação, discussão de temas político-sociais, como a hierarquização do mundo (se ela vai ser feita de uma raça alienígena sobre a Terra, ou de homens brancos sobre mulheres negras) e discutir tópicos tão próximos da nossa atualidade, como o afrofuturismo, estética tratada por Butler e que hoje está presente por exemplo em Pantera Negra, novíssimo filme da Marvel/Disney e que bebe das fontes afrofuturistas do sci fi.

Pelas curtas e não definidas páginas de Philip K. Dick, que Blade Runner surgiu, nosso primeiro ponto do texto. O título do filme não é citado no livro, tampouco existe de fato uma aproximação, mas o que Hollywood não faz por palavras sexys o bastante para chamar público? Mas vejam, desta vez não é somente o título sexy, é uma narrativa distópica, um futuro sombrio, carregado de mazelas... E um protagonista cheio de sexy appel, um jovem Harrisson Ford com seu sobretudo amarronzado, uma Sean Young como dama fatal e um vilão egocêntrico e psicótico... Blade Runner teve tudo para ser normal, comum; mais um bagulho, e mais de trinta anos depois de seu lançamento, em 1982, um dos termos nunca utilizados para definir sua composição é justamente esse: normal.

Quando os planos se abrem, encaramos a Los Angeles de 2019 pela primeira vez: nociva, carregada de um sentimento tóxico, de um mundo já estabelecido, e obviamente a trilha sonora composta por Vangelis, com seus sintetizadores carregados unificam uma mescla singular, a de um universo e estética própria.

Seus minutos iniciais são cheios de mistério, a atmosfera neo-noir, impregnada na fumaça branca que foge do cigarro nos tons escuros, alça voo sobre qualquer tipo de distopia esteticamente brega, logo em seguida somos apresentados ao profeta da nossa jornada, Rick Deckard, o proletário comum, o operário do mundo futuro, Deckard é caçador de 
andróides, na verdade, replicantes, há uma confusão sobre os termos, resumidamente, andróide era um termo frio demais para um filme, por isso a invenção de replicantes, criaturas biomecânicas idênticas ao ser humano e que são proibidas na Terra. Deckard se depara então com sua meta: aposentar (assassinar) os replicantes da Nexus-6, uma linhagem fugitiva que deixaram as colônias interplanetárias e que vagueiam por uma Los Angeles mortífera.

E o mundo de Blade Runner começa a tomar forma, pela direção de Ridley Scott, uma fotografia particular e uma trilha sonora inédita, é possível identificar traços de um mundo próprio, de um visual próprio, juntamente com Neuromancer (1984), romance de William Gibson e Akira, animação japonesa de 1988, podemos compor a trindade do gênero cyberpunk: não só um gênero midiático, mas uma composição estética e política de se vivenciar o mundo.

Essa Los Angeles de 2019 é o cenário apoteótico onde Deckard vive sua jornada em busca dos andróides, onde o blues futurista toca, onde percebemos uma presença oriental gigantesca, onde o pano de fundo político é justamente de controle corporativo sobre o Estado e onde a própria vida, e seus diversos significados perdem o sentido real de existência.

Pensar nossa realidade por meio do cyberpunk e da ficção científica é pensarmos também em como essas produções e visões de mundo reverberam na nossa atualidade e estão presentes em nosso cotidiano, se torna influente estar dentro do imaginário psicosférico e se presenciar ou sentir-se imerso numa estética do tipo. Vejam, o que caracteriza tais gêneros? Experiências de pensar, além do imaginar filosófico, estas experiências filosóficas conduzem uma discussão presente também na antropologia filosófica, matéria de estudo de inúmeros filósofos, o cyberpunk como sub-gênero da ficção científica e a própria ficção científica sintetizam uma nova estética de se vivenciar a realidade, de sentir a realidade.

Já se pegou ouvindo blues e pensando melancolicamente sobre o mundo, enquanto observa prédios por uma janela? Ou se pegou preocupado com um aplicativo instalado no seu celular, quem sabe com algum match adquirido, já sentiu e vivenciou momentos que se prendem nas suas memórias e se perdem com extrema rapidez? 
O cyberpunk surge como uma forma estética de discutirmos a nossa realidade vivenciada, nossas experiências cotidianas e até mesmo nossas políticas modernas, se torna essencial trazer um gênero que sintetiza algo além do pensamento para a nossa vivência atual.

Friedrich Nietzsche, filósofo alemão, sujeita o termo "super-homem", o estágio além do homem, onde superamos o último-homem, estado o qual vivemos. Este super homem teria uma nova visão de mundo, de valores, de sociedade, de ser homem, superaria o niilismo e o pessimismo. Nos mundos do cyberpunk, o niilismo venceu.

Os elementos mais notados na criação cyberpunk são essenciais para pensarmos a nossa própria realidade, há um desprendimento com os valores, com as invenções da própria vida, o mundo mergulhou em um período de encanto com as trevas, a tecnologia suprime as vontades humanas, o niilismo engoliu as leituras materialistas de mundo, racionais, um dos exemplos claros são as próprias relações entre os seres humanos e outras espécies, a demonstração máxima disso é a própria prosa de Philip K. Dick, com o seu primordial Andróides Sonham com Ovelhas Elétricas? (1968) texto base para o filme Blade Runner.

Na prosa, acompanhamos Deckard, que surge como o homem comum, o trabalhador mais comum ainda, casado, vive uma realidade também hostil, estamos em uma San Francisco, grande parte dos seres humanos fugiram para as colônias, a esposa de Deckard, Iran, sofre de depressão e o sonho do homem é ter um animal real, que preencheria seu vazio de status numa sociedade decadente, todos vivem sob a sombra de Mercer, a divindade do Mercerismo, uma religião inventada por meio de uma máquina, a "Caixa de Empatia", mecanismo que força os seres humanos a se interligarem empaticamente com um velho senhor escalando uma montanha, enquanto rochas caem. Na epopeia niilista de Deckard, o vemos conhecer personagens, ter contato com outros campos da sua realidade, assassinar andróides, se relacionar com andróides, conceber dúvidas sobre sua existência... E retornar para seu estágio comum, nos versos finais, quando retorna para casa, cansado com seu sapo mecânico. O cenário visual do livro é narrado como se o lixo, o chamado bagulho, invadisse o resto do mundo, cenário muito próximo do cyberpunk como o conhecemos hoje, tanto em obras artísticas, produções cinematográficas, literárias e até mesmo em jogos digitais. PKD vai além então, ao criar máquinas religiosas, criadores de emoções e outras inúmeras invenções tecnológicas que suprimem necessidades 
emocionais-humanas, no próprio livro identificamos um traço terrível desse futuro não tão distante: as personagens artificiais têm muito mais empatia do qualquer ser humano.

Os chamados andróides vivem em uma coletividade positiva, cuidando um dos outros, se tratando, como também é demonstrado no filme, os replicantes são capazes de ter empatia entre si, de se imaginarem e se posicionarem como o outro, além de desenvolverem um senso de igualdade de espécime enorme, enquanto os próprios seres humanos não desenvolvem esse tipo de emoção.

Os gêneros cyberpunk são capazes de desenvolver isso em comum, a extrema desconexão de nós como seres humanos e ao mesmo tempo um estrito ligamento. Na noviça continuação, Blade Runner 2049, de Dennis Villeneuve, vemos o mesmo eco: no futuro mais distante ainda, os replicantes agora vivem "soltos" e amarrados, presos nas estruturas sociais de escravidão, mas capazes de se prenderem em qualidades supostamente humanas, nosso protagonista, K., acredita ser especial (como todo ser humano que pisa vivo), desenvolve um romance com uma inteligência artificial (imaginem um Zygmunt Bauman futuro discorrendo sobre as relações mais líquidas-ainda) e tenta ser humano, tenta se tornar humano, o que poucos notam é a incrível capacidade que todos os replicantes do filme têm em desenvolver empatia uns pelos outros, uma preocupação angustiante tanto por humanos como por replicantes... Enquanto os seres humanos não.

Tanto na prosa, como na narrativa visual de Blade Runner, somos apresentados para um problema em comum: o que define ser humano, quais são as barreiras entre artificial e natural? E a antropologia cultural surge de supetão, as discussões de natureza humana, o que caracteriza um ser humano e nossas convenções são também perguntas angustiantes nas duas obras. Assim, partimos para diferentes leituras dessa real distinção entre máquinas e seres humanos, enquanto muitas leituras tratam de forma mais biológica e fria, os Replicantes não são humanos, pois são artificiais, construídos por humanos, e assim, supostamente, sem natureza, sem a chamada "alma".

O que define uma máquina? E uma inteligência artificial? Nossa neurociência se encontra em um estado inicial, ainda não somos capazes de explicar totalmente quais aspectos o cérebro tem para ser provido de forma personificada a existência de uma consciência e mesmo que se pudéssemos o entendimento poderia cair de forma muito crua, como tentar 
explicar toda a consciência através de processos bioquímicos e biofísicos que são fermentados em outros tipos de processos mentais, essa ideia de explicar a consciência se torna uma das respostas mais árduas de todos os campos, é tentar conciliar dois estudos que embora tenham ligação muitos tentam separar, o campo do físico e o da metafísica, para John Searle e Daniel Dennett estamos parados diante os problemas da consciência como os biólogos diante os fenômenos vitais até o novo século $\mathrm{XX}$, ou seja, ainda não temos total certeza do que estudar, e de forma bastante estranha o campo de pesquisa das consciências robóticas e de inteligências artificiais cresce cada vez mais.

De forma vaga podemos definir que a consciência só existe com experiência. A experiência empírica sensorial é fundamental para qualquer tipo de pensamento, ideia e formatação consciente interna, os nossos sensores são os principais captadores de qualquer experiência externa, se física, auditiva, etc. A consciência vive dependente da experiência externa e junto a isso se torna quase integrada a nossa mente, assim interligando realidade externa e interna. Somos eternas máquinas que reagem, se apropriam, criam, fermentam, queimam, somos usinas.

O filósofo australiano D.M. Armstrong analisa a consciência humana com duas modalidades fundamentais, a perceptual e a introspectiva. Para usar nossos sentidos para ouvir, sentir e ver o mundo externo estamos vivenciando e exercendo a consciência perceptual, acordados, alertas, e talvez justamente por isso que quando uma pessoa está em um estado de adormecer ou quando sofre de algum problema sendo induzida ao coma ela perdeu a consciência, para Armstrong a modalidade perceptual de consciência pode ser definida como a experiência que nossa mente têm que seria a realidade externa.

A consciência introspectiva seria a autoconsciência, a reflexão, a experiência interna e assim um dos próprios estados mentais. Sensações, sentimentos, percepções, todas essas formações internas como a própria reflexão são formas que a consciência introspectiva se demonstra, essa experiência interna é real e é de forma bastante árdua que podemos defini-la, se resultado de alguma ponte biológica, bioquímica e afins, ou pertencente a outro tipo de experiência metafísica ou transcendental.

Por essas análises mais frias, podemos chegar enfim numa visão mais charmosa e mais interessante: a das máquinas desejantes, conceito proposto por Gilles Deleuze e Félix 
Guatarri em seu Anti-Édipo (1972), todos nós, seres humanos somos máquinas desejantes, eternas usinas de desejos, energias e anseios, cada célula, cada órgão, cada especificidade humana é uma máquina, nosso corpo é uma casca, apenas, nossa real maquinaria está na interioridade, nas minuciosas e poderosas capacidades de organização, mutualidade e convivência.

O que define precisamente as máquinas desejantes é o seu poder de conexão ao infinito, em todos os sentidos e em todas as direções. (DELEUZE, G. \& GUATARRI, F. 1972, O Anti-Édipo)

Nessa maneira de leitura de realidade, onde nós, somos máquinas desejantes, podemos ver uma proximidade bastante afável com os Replicantes e Andróides de Blade Runner, também sonhadores, também participantes desses circuitos e que partilham de uma experiência em comum conosco: o invólucro corpóreo, suas carapaças são afetadas pelos ciclos e meios sociais, como nós, somos frutos de nossas experiências culturais e sociais, como os Replicantes, como os Nexus-6, que iniciam uma revolução por sua posição inferiorizada em sociedade, hostilizada e escrava, respostas desejantes em meio ao tenebroso circuito social que se instalara em suas realidades, todos nós somos Replicantes, nascemos de determinada forma, com determinadas funções, dentro de uma hierarquização social muito presente, somos levados para determinados circuitos e prisões, para eles, correntes? Para nós, dogmas religiosos, sociais, políticos, passamos pelas mesmas provações, de vivenciar ações, pensar, experimentar e repensar maneiras de se inventar, os Replicantes vivem numa marginalização eterna, a de eterna exclusão social, de externa separação de classes e também por esse processo Edípico da coisa, os Replicantes também são imersos nessa lógica capitalista de edipianizar suas estruturas sociais, suas convenções, eles já estão infectados pela psicanálise cotidiana e comum do modelo de Édipo, mas encontram na coletividade e nas experimentações revolucionárias do desejo uma nova vivência, uma nova experimentação existencial, como nós, buscam mais vida, maneiras novas de experimentar a vida e nossos delírios, Roy Batty na prosa encontra sua escapatória nas drogas: era um Replicante meio farmacêutico que misturara inúmeras drogas e tivera uma experiência além de tudo, não só os Replicantes, mas os próprios humanos vivem numa condição desenvolvida do capitalismo plena, a de controle exacerbado e geral, não por meio de uma ditadura como em outras obras distópicas, mas pela religião Mercerista, pelas tecnologias emocionais, por uma série de degradantes 
fatores psicológicos, a experimentação e a vontade de se descobrir acaba então inaugurando uma nova mensagem na obra, a de renovação, a de buscarmos ainda mais nossas máquinas desejantes.

Roy Batty e os outros replicantes são nossos eternos revolucionários, inauguradores da revolução e quem sabe além do homem, afinal a pergunta não é se os Replicantes são seres humanos, mas se também são máquinas desejantes, como nós, e por fim, que não deixemos o espírito revolucionário morrer, e sim reacender, em tempos de mazelas, nós somos as máquinas revolucionárias responsáveis pelas mudanças, e que venham mais revoluções replicantes. 